\title{
Globalizing nursing science: analysis of nursing's participation in the open access movement from 1993 to 2014
}

\author{
Jan M. Nick ${ }^{1,2}$ \\ ${ }^{I}$ Professor, School of Nursing, Loma Linda University, Loma Linda, California, USA \\ ${ }^{2}$ Dean, Department of Nursing, Saniku Gakuin College, Otaki-machi, Japan \\ E-mail:jnick@llu.edu
}

\begin{abstract}
Background: The traditional journal subscription model restricts access to scholarly information since proprietary fee-based databases charge high subscription fees, do not provide access to all journals in the same geographic region, and include minimal access to research journals from other countries. This practice insulates nursing knowledge, causes duplication rather than replication of research, and results in a lack of breadth and depth to our science.

Objective: Describe the state of nursing participation in the Open Access (OA) movement.

Methods: Using a descriptive, exploratory approach, all nursing journals in the Directory of Open Access Journals (DOAJ) data warehouse were extracted, tagged, and analyzed.

Results: Sixty-two nursing journals from 23 countries have registered as Open Access. Brazil publishes the largest number of OA nursing journals (14), followed by the U.S. (9) and Spain (9). Two countries publish four OA nursing journals (Canada, Iran), while the remaining 18 countries publish one or two OA nursing journals. Fifty percent publish in either Spanish, Portuguese, or Spanish/Portuguese, while another one-third (32\%) publish in English. Importantly, $82 \%$ of OA Nursing journals do not require article processing charges; of those who do have APCs, the majority (66\%) are $\$ 300$ or less.

Conclusions: Although nursing participated early in the OA movement, growth has been consistent but sluggish. Neither the size of the country nor economic status seem to have a strong influence on decisions to produce OA nursing journals. Encouraging participation in OA will advance the science of nursing by allowing broader and more coordinated access to information to the global community.
\end{abstract}

Keywords: Dissemination Science; DOAJ; Globalization; Nursing Science; Open Access.

\section{Introduction}

In today's digital world, the landscape of scientific information is rapidly changing. With the emphasis on scholarly publishing, coupled with the many publication options now available, nursing scientists need to be aware of the trends occurring with dissemination of scholarly information. Not only is information accessible online using the traditional subscription based model, recent developments in a new venue for scholarly publishing - namely Open Access (OA), is revolutionizing information access. Advances in technology, growth of the internet, maturation of the evidence based movement, and the emergence of the OA movement has created a new subfield within information literacy which is a competency or standard for practicing nurses amongst leading nursing organizations (American Association of Colleges of Nursing 2008, National League for Nursing Position Statement 2008, HIMSS 2011). Historical beginnings and benefits of the Open Access movement have been identified previously in the nursing literature (Nick 2011), as well as cautionary tales about the emergence of deceptive and predatory practices of some OA publishers (INANE Predatory Publishing Practices Collaborative 2014).

The purpose of this article is to investigate, define, and inform the global nursing community about nursing's participation in publishing scholarly journals using the Open Access platform in order to elucidate and encourage broader dissemination of information and globalize the science of nursing. Implications for publishing and knowledge dissemination are covered with emphasis on options available to nurse scholars. Recommendations for further research are embedded with the findings in order to encourage nurse scientists to develop and enlarge the body of research germane to the science of dissemination.

\section{Review of the literature}

To understand our participation, nursing must first understand the terminology. Phrases like subscription based access, Open access, Green and Gold Open Access, author-choice access, hybrid journals, and embargo/delay Open Access are important concepts to distinguish. Purely defined, Open access is the:

Free availability on the public internet, permitting any users to read, download, copy, distribute, print, search, or link to the full texts of these articles, crawl them for indexing, pass them as data to software, or use them for any other lawful purpose, without financial, legal, or technical barriers other than those inseparable from gaining access to the internet itself through the practice of self-archiving of preprints and postprints, and transitioning to OA journals (Budapest Open Access Initiative 2002).

Subscription-based access is defined as the traditional model we currently use where scholars submit their work, colleagues conduct peer-review and recommend or reject, and a for-profit com- 
pany publishes the article in one of their journals and charges a fee for others to access the information either through printed or electronic journals. Historically, societies typically published the scientific journals prior to the 1960s. Then, publishers recognized the profitability of acquiring journals from these societies, purchased the rights, and began the for-profit scholarly publishing model currently in existence (Edwards \& Shulenburger 2003). Since the emergence of the Open Access movement, these same for-profit publishers have creatively produced a mixture of alternate formats for their for-profit journals; the extent of this practice has not been characterized yet and offers future research possibilities.

The traditional model of purchasing proprietary fee-based databases to access scholarly information creates several problems for institutions from developed as well as developing countries. First, subscription fees inhibit many institutions from purchasing multiple proprietary datasets or large datasets, which prevents access to scholarly information. Another problem with the current dissemination practices is that, on average, subscription fees have increased $10 \%$ annually each year for the last 10 years, making purchases even more difficult for consumers (Liesengang 2013). A third problem is the duplication of journals included in each bundled database when libraries purchase multiple proprietary feebased databases. This condition reduces return on investment (ROI) for institutions. Preliminary research revealed in one institution, there was $42 \%$ duplication of nursing journals found in the bundled databases (Nick 2013). Thus, even the most well-outfitted libraries are wasting financial resources because of duplication in each proprietary databased purchased. Fourth, these databases do not capture all the journals published in a country where the bundled database is purchased. This author's experience has also found a lack of access to journals published in country that are not included in the bundled databases. Finally, proprietary fee-based databases do not include a sufficient number of journals from the global nursing community, thus reducing knowledge transfer to other countries. For example, databases of bundled journals at one large health science institution offered a smattering of nursing journals from other highly developed countries (Nick 2013). These five factors indicate that the traditional journal subscription model insulates nursing knowledge, causes duplication and rather than replication of research, and results in a lack of breadth and depth to our nursing science. All these conditions make evidencebased practice difficult for nurses in various parts of the world.

The recent development of the Open Access platform for publishing scholarly information is one solution to this problem of lack of access. This movement helps answer the question "Who is privy to scientific information?" Basic sciences and biomedical sciences have embraced the open access movement, as recent research reveals up to $50 \%$ of articles in PubMed are estimated to be open access, a rise from $26 \%$ in 2005 (Kurata et. al. 2013). To date, Nursing's participation has not been described nor documented, yet this information is critical to help authors decide which journal to submit for publication, as well as help other nurses gain access to information.

Recent policy changes have occurred from major private institutions and governmental agencies supporting the Open Access movement. Changes now require recipients of grant-sponsored research to publish results in journals that support Open Access. For example, the U.S. government mandated that in 2008 all NIHsponsored research be published in PubMed Central (PMC), an open access repository (NIH Public Access Policy 2008). Since recent data from PMC indicate only a quarter of all visitors to that website are from academic institutions, this demonstrates a great need for scholarly information outside academia, where hospitals, clinics, and offices do not have the financial backing required to have sufficient information resources (Kaiser 2010). The U.K. based Wellcome Trust adopted a policy beginning October 2013 that all researchers receiving grant funding must submit published results to PubMed Central or Europe PubMed Central in order to make results available for free (Wellcome Trust 2013); Canada has followed suit with a PMC Canada initiative (National Research Council Canada 2009).
Additionally, Britain's government recently made a daring yet calculated move to ask all scholarly journals to move to the OA publishing platform (Research Information Network 2013). Moving globally, the World Health Organization (WHO) announced in January 2014 that all WHO-authored or WHO-funded research published in non-WHO publications, such as external journals and books must be published using the Open Access platform, effective July 2014 (World Health Organization 2014). Even the publisher of the prestigious Nature Journals, as of October 2014 is exploring open access models, and requires authors to pay article processing charges (APCs) (Nature Publishing Group 2014). Policy statements from these organizations state their belief in free access of scholarly information to all scientists.

\section{Research questions}

To inform nursing about the science of dissemination using the OA platform for publishing, there were three research questions addressed that will complete an initial characterization of nursing's participation in the OA movement. Namely:

1) What were the initial efforts at publishing OA nursing journals, and how has it grown into the current state of participation?

2) What is the state of article processing costs (APCs) required when publishing in OA Nursing Journals?

3) What languages are represented in the publications of $\mathrm{OA}$ nursing journals?

\section{Methods}

\subsection{Design}

Using a descriptive, exploratory framework, the author conducted a survey of nursing journals registered in the Directory of Open Access Journals (DOAJ) data warehouse and obtained records from the beginning of the registry until December 2014. DOAJ is a registry of all open access scientific journals from various basic and applied sciences. This registry was chosen as a valid representation of the state of Open Access nursing journals because it: a) is the oldest and largest global registry of scientific journals using the Open Access platform for publishing, b) is recognized as an authoritative list of scholarly, peer-reviewed, fully open access journals, c) works closely with other agencies that set high standards for scientific publishing, such as the Committee on Publication Ethics (COPE), Open Access Scholarly Publishers Association (OASPA), and World Association of Medical Editors (WAME), d) sets 16 principles of OA best practices (http://doaj.org/bestpractice) that journals have to meet before being admitted, and e) requires registered OA journals to re-apply to the repository regularly in order to demonstrate meeting updated standards. Having to meet all these conditions supported the assumption that journals admitted to DOAJ are of similar quality as subscription-based journals since they have similar quality control procedures in place.

\subsection{Procedure}

DOAJ offers either download of metadata (all journals in DOAJ) or an advanced search options with individual record downloading. Using the advanced search function and delimiting search parameters provided the population of nursing journals. Three search parameter scenarios were used in order to determine which parameter provided the most nursing journals. By using the advanced search option, and filtering "journals" rather than articles, choosing "subject" in the drop down menu, and specifying "nursing" resulted in 56 journals. When the drop down box was changed to "keyword" in the search box, then adding the search term "nursing," 74 records were obtained. By using "Search All" feature as the search parameter in the drop down menu, and typing "nursing" in the search term box, 95 journals were identified. This last search technique was used for the final dataset. Journal infor- 
mation was individually downloaded to Excel spreadsheet for review and determination of inclusion in the analysis. In addition, the three search results were tested using three common browsers: Explorer $^{\mathrm{TM}}$, Firefox ${ }^{\mathrm{TM}}$, and Google Chrome $^{\mathrm{TM}}$. There were no differences in results obtained.

\subsection{Inclusion/exclusion criteria}

To be included in the final dataset for analysis, any journal with "nursing" in the title was included. Other journals were then included if they either listed "nursing" as the first descriptor in the "subject" heading, or had the term "nursing" listed either first or second in the "keywords" heading. If any question remained about including/excluding a journal after this initial collection of journal titles, the journal contents were checked online and article titles were reviewed. If the majority of articles in the journal were specific to nursing, the journal was included. Of the 95 obtained in the initial download, 62 OA nursing journals were retained for final analysis of this descriptive, exploratory research while 33 journals were eliminated from the sample as they did not meet any of the three conditions for inclusion.

\subsection{Reliability/validity of journals included in the final dataset}

Evidence to support validity of the nursing journals was established in four ways. In January 2014, DOAJ removed any journals from the registry not offering Open Access any longer. No nursing journals were removed; thus all nursing journals obtained during the initial search process in the DOAJ registry were considered valid Open Access journals. Second, the list of journals excluded as well as the list of journals included in the sample were reviewed by two informatics nurse educators to establish content validity; CVI between the author and the content experts was $98 \%$ agreement. One journal, recommended by one of the informatics nurses did not meet inclusion criteria but did list several nursing authors in the tables of contents. Since there were other health journals excluded that had this same condition, it was not retained. Although the contents were suitable for nurses to read, the journals themselves were not primarily nursing focused. Third, the author checked each nursing journal included in the analysis for verification and currency of publications by visiting the associated website of each nursing journal. Fourth, journals were crosschecked against Beall's list of Questionable Journals (http://scholarlyoa.com/2014/01/02/list-of-predatory-publishers2014/); no journals included in the analysis appeared on this list.

\section{Findings}

The dataset obtained from DOAJ provided multiple points of information to answer the research questions. The nursing journals were registered under one of thirteen mutually exclusive "subject" headings; eighty-one per cent of the nursing journals fell under the subject heading of "nursing, medicine" while the rest were identified from a variety of headings as shown in Table 1.

\subsection{Initial efforts at publishing $O A$ nursing journals and current state of nursing's participation}

From the first OA nursing journal in 1993, until December 2014 62 nursing journals from 23 countries have been registered as Open Access as shown in Table 2. Currently, the countries publishing the most OA nursing journals include Brazil (14), Spain (9), the U.S. (9), followed by Iran (4) and Canada (4). The rest of the participating countries publish one, or two OA nursing journals.
Table 1: Number of Journals and Subject Categories Used by Nursing Journals in DOAJ as of December 2014

\begin{tabular}{lll}
\hline & "Subject" categories & $\begin{array}{l}\text { No. of } \\
\text { journals }\end{array}$ \\
\hline 1 & $\begin{array}{l}\text { Diseases of the genitourinary system. Urology, Spe- } \\
\text { cialties of internal medicine, Internal medicine, Medi- } \\
\text { cine, Nursing, Medicine }\end{array}$ & 1 \\
& $\begin{array}{l}\text { Ethnology. Social and cultural anthropology, Anthro- } \\
\text { pology, Geography. Anthropology. Recreation, Nurs- }\end{array}$ & 1 \\
& $\begin{array}{l}\text { ing, Medicine } \\
3\end{array}$ & Geriatrics, Special situations and conditions, Internal \\
4 & medicine, Medicine, Nursing, Medicine & 1 \\
5 & Medicine (General), Medicine & 1 \\
6 & Nursing, Public aspects of medicine & 1 \\
7 & Nursing, Geriatrics & 1 \\
8 & Nursing, Gynecology and obstetrics & 1 \\
9 & Nursing, Medicine & 50 \\
10 & Philosophy (General) & 1 \\
11 & Public aspects of medicine, Medicine & 1 \\
12 & Public aspects of medicine, Medicine, Nursing, Medi- & 1 \\
13 & cine & 1 \\
& Special aspects of education, Education & $\mathbf{6 2}$ \\
\hline
\end{tabular}

${ }^{\mathrm{a} N u r s i n g}$ journals from these categories were used in the analysis

Table 2: Number of OA Nursing Journals, and Status of Article Processing Charges by Country of Publication. From 1993-2014.

\begin{tabular}{|c|c|c|c|}
\hline $\begin{array}{l}\text { Countries with } \\
\text { OA Nursing } \\
\text { Journals indexed } \\
\text { in DOAJ }^{\mathrm{a}} \\
\end{array}$ & $\begin{array}{l}\text { No. of OA Nurs- } \\
\text { ing Journals in } \\
\text { DOAJ as of De- } \\
\text { cember } 2014\end{array}$ & $\begin{array}{l}\text { No. of OA Nursing } \\
\text { Journals with Arti- } \\
\text { cle Processing } \\
\text { Charge (APCs) }\end{array}$ & $\begin{array}{l}\text { APC } \\
\text { amount }^{b}\end{array}$ \\
\hline Australia & 1 & 0 & \\
\hline Brazil & 14 & 1 & $\$ 34$ \\
\hline Canada & 4 & 1 & $\$ 300$ \\
\hline Chile & 1 & 0 & \\
\hline Colombia & 2 & 0 & \\
\hline Costa Rica & 1 & 0 & \\
\hline Cuba & 1 & 0 & \\
\hline Egypt & 2 & 1 & $\$ 800$ \\
\hline Greece & 2 & 0 & \\
\hline Iran & 4 & 0 & \\
\hline Italy & 1 & 0 & \\
\hline New Zealand & 1 & 1 & $\$ 1695$ \\
\hline Norway & 1 & 0 & \\
\hline Portugal & 1 & 0 & \\
\hline South Africa & 1 & 1 & $\$ 82$ \\
\hline South Korea & 1 & 0 & \\
\hline Spain & 9 & 0 & \\
\hline Thailand & 1 & 0 & \\
\hline Turkey & 1 & 0 & \\
\hline $\begin{array}{l}\text { United Arab } \\
\text { Emirates }\end{array}$ & 1 & 1 & $\$ 150$ \\
\hline United Kingdom & 2 & 1 & $\begin{array}{l}\$ 2,215 \\
\$ 275 ;\end{array}$ \\
\hline United States & 9 & 4 & $\begin{array}{l}\$ 999^{c} \\
\$ 200 \\
\$ 160\end{array}$ \\
\hline Venezuela & 1 & 0 & $\leq \$ 3300=$ \\
\hline Summary & 62 & $11(18 \%)$ & $\begin{array}{l}\leq \$ 800= \\
1 \\
\geq \$ 900= \\
3\end{array}$ \\
\hline
\end{tabular}

${ }^{a}$ Language of country where journal is published does not necessarily match publication language in Table 3 .

${ }^{\mathrm{b}}$ All money currencies converted to \$USD

${ }^{\mathrm{C}} \mathrm{APC}$ price quoted for this journal is per first 10 printed pages, with each additional page $\$ 50$

Brazil was the first country to publish an OA nursing journal, followed by Cuba in 1995. Since then, there has been a slow but incremental rise in the number of OA nursing journals joining the DOAJ registry annually, demonstrated in Fig. 1. Most of the countries who participated early on by publishing the initial OA nursing journals (Brazil, Spain, and the U.S.) have consistently added new OA journals every one to two years since then, as seen in Fig. 
2. The median lag time between publication start date and admittance date in to DOAJ is two years for nursing journals, while the mode lag time is one year. Fig. 2 also shows OA nursing journals that started since 2012 have had an even shorter lag time.

In the future, as OA grows, the number of nursing and medical journals will provide overall depth of the science. Interestingly, neither the size nor economic status of the country seem to be a factor in deciding to publish OA nursing journals. Some economically developed countries are noticeably absent from the list and do not publish any OA nursing journals, or only publish one or two journals. And, remarkably, some smaller or economically challenged countries are leaders in OA publishing of nursing journals. Determining factors used to decide to publish or not to publish is worthwhile research, as this information will serve to encourage more OA publishing in nursing.

\subsection{Article processing charges (APCs) associated with publishing in OA nursing journals}

Although a vocal argument against OA journals has been the potential cost to authors to have their article published in an OA journal (called article processing charges, or APCs), it is heartening to see $82 \%$ of OA nursing journals in DOAJ do not have APCs as seen in Table 2. Only 11 of 62 (18\%) OA nursing journals required APCs which is much lower than the APC rate of 59\% identified for other biomedical sciences (Solomon \& Björk 2012). Additionally, the average cost of APCs in OA nursing journals is also very low--7 of the 11 journals $(64 \%)$ had APC charges of $\$ 300$ or less, while three OA nursing journals set APCs of $\$ 900$ or more. Often, publishers will reduce or waive APCs in instances of demonstrated economic hardship, or, if the institution has a library membership with the publisher. In the future, characterizing the practice of paying for APCs or receiving a fee waiver in OA nursing journals will be an important question to answer in order to boost support of OA publishing in nursing journals. Identifying business models for OA nursing journals will also aid new start up journals to maximize growth yet minimize APC requirements.

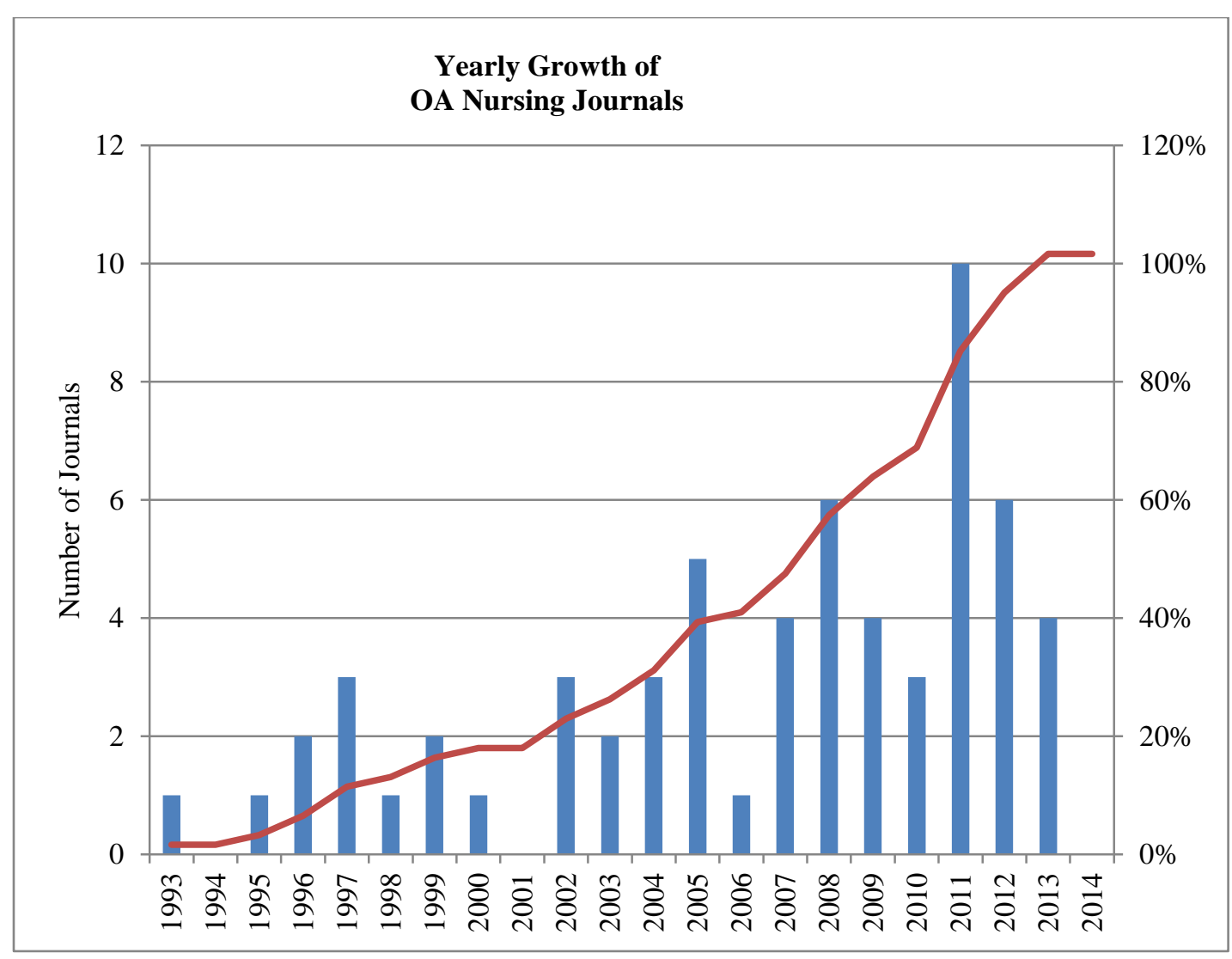

Fig. 1: Trended Growth Line of the Sixty-Two OA Nursing Journals, by Year. 


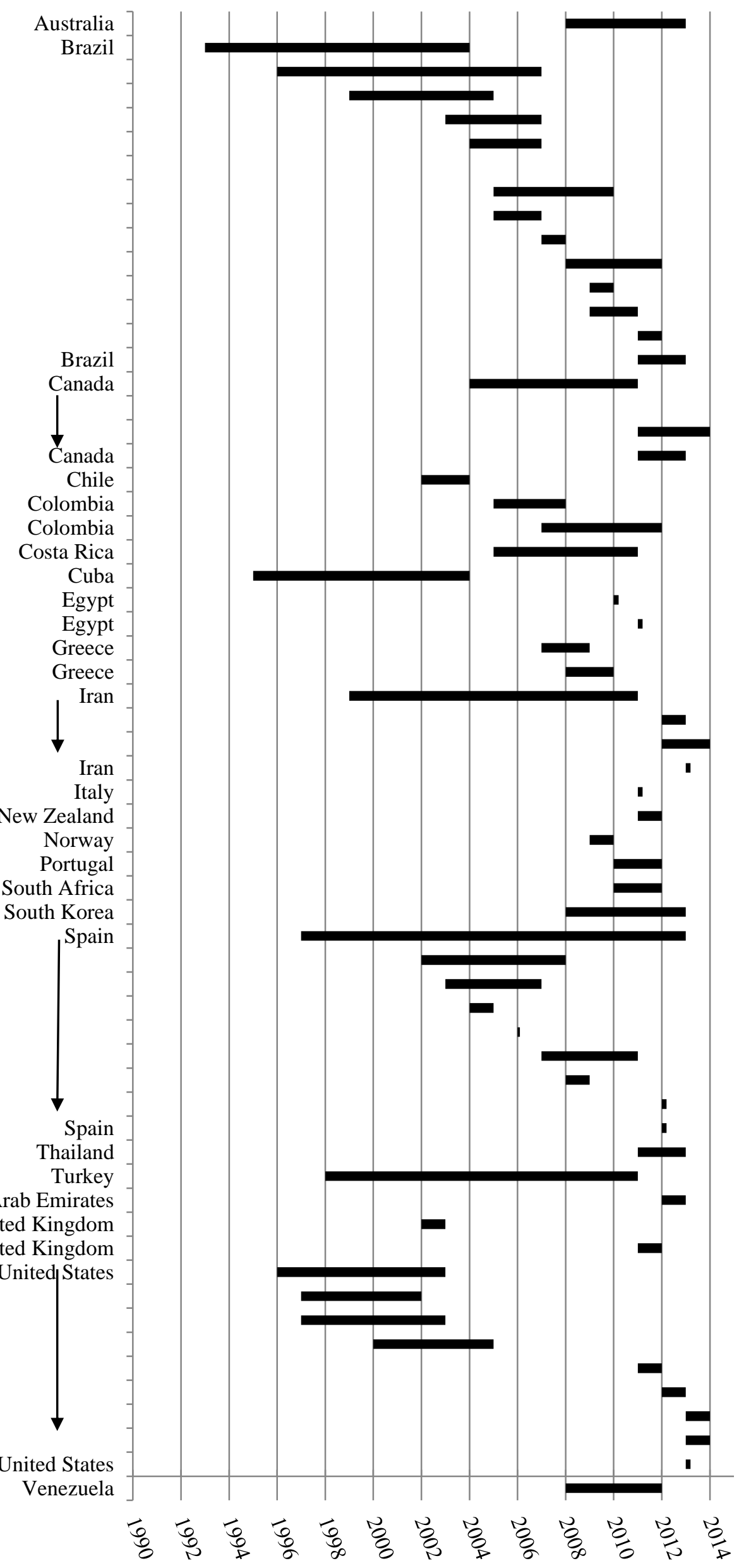

Fig. 2: Lag Time between Start of Journal and Admittance to DOAJ 


\subsection{Languages represented in OA nursing journals}

To help nursing achieve global representation of the science, determining available languages offered in Open Access is necessary. Table 3 shows a third of the OA nursing journals were in English (32\%), 15\% were in Spanish, 15\% were in Portuguese, and another $20 \%$ were in a combination of Spanish, and Portuguese. Combined, Spanish and Portuguese made up 50\% of OA Nursing journals. Publishing journals in this combination has merit, as native Spanish and Portuguese speakers have facility with reading the other's language due to similarities in root word typology and morphology (Amaral \& Carvalho 2014), and orthographic transparency (Sheets 2014). In total, these three languages (English, Spanish, and Portuguese) composed $82 \%$ of the OA nursing journals. The other $18 \%$ of OA nursing journals are published in a variety of languages. As more countries participate in the Open Access movement, the potential addition and shift in languages published will be important to monitor.

Table 3: OA Nursing Journals by Language, in Alphabetical Order

\begin{tabular}{llc}
\hline Language $^{\mathrm{a}}$ & $\begin{array}{l}\text { No. of OA Nursing } \\
\text { Journals }\end{array}$ & Percentage $^{\mathrm{b}}$ \\
\hline Chinese $^{\mathrm{c}}$ & 2 & $3 \%$ \\
English $^{\text {French or French/English }}$ & 20 & $32 \%$ \\
Greek & 2 & $3 \%$ \\
Korean/English & 1 & $2 \%$ \\
Norwegian & 1 & $2 \%$ \\
Persian & 1 & $2 \%$ \\
Portuguese & 3 & $5 \%$ \\
Spanish & 9 & $15 \%$ \\
Spanish/Portuguese combina- & 12 & $15 \%$ \\
tion & & $19 \%$ \\
Thai & 1 & $2 \%$ \\
Turkish & 1 & $2 \%$ \\
Total & 62 & $100 \%$ \\
\hline
\end{tabular}

${ }^{\mathrm{a}}$ Many non-English OA nursing journals do provide abstracts in English.

${ }^{b}$ Rounding rule applied.

${ }^{\mathrm{c}}$ Both journals are published in the U.S.; language of publication different from publication country.

${ }^{\mathrm{d} J o u r n a l s}$ from this category identified Spanish, Portuguese, and English combination, but only one journal had full text articles in English. Others offered English titles.

\section{Discussion}

This article outlines the state of nursing participation in the Open Access movement. Although the concept of open access is mature in other sciences, these findings demonstrate that nursing's participation began early, but growth continues at a slow pace. The research also showed another difference - that OA nursing journals have very low APCs. Given that very few OA nursing journals actually charge APCs, that required costs are lower than other disciplines, and that publishers may waive the costs, a conclusion is APCs should not be a deterrent to publishing in OA journals. In fact, in order to benefit the global nursing community, a question germane to nurse scientists is "Why not publish in an OA journal and disseminate the information globally to all nurse scientists?' Research in other disciplines has demonstrated that OA journals offer a clear citation advantage (Wolrabe \& Birkmeier 2014, Atchison \& Bull 2015,) and that OA journals are approaching similar scientific impact and quality as subscription journals (Björk \& Solomon 2012). Does publishing in OA nursing journals offer nursing a citation advantage? Further research must determine this answer.

The internet has the ability to equalize the information flow to all countries - the International Council of Nurses (ICN) recognizes this potential, and has created a position statement to call for equity in communication access. Without it, a large portion of nurses around the globe will remain disenfranchised (ICN 2014). Open Access, using the internet as the venue, will provide up to date, scientifically supported evidence and begin to equalize practice. If nursing does not participate, scientific information will remain in silos, and full access to nursing phenomena will not be possible for developed as well as developing countries. Nurse scientists all around the world will be disadvantaged. This condition can be seen as an opportunity to develop capacity globally.

The thirteen categories used by publishers when applying for admittance into DOAJ as shown in Table 1, also provides opportunity for consolidation. Only four categories displayed extant language that the journal's primary audience was nursing. This practice may cause several journals to be missed when nurses use the DOAJ repository to find OA nursing journals. A recommendation for publishers would be to make nursing journals more visible and easier to find by using "nursing" as the first phrase of either subject or keyword terms. Not to do so only hampers the global population of nurses from finding these journals.

A last consideration is, Nursing's participation in the OA movement may actually be higher, as this research used the DOAJ registry as an indicator of the efforts nursing has done with publishing in the OA platform. There may be other nursing journals currently in publication using the OA format, but have not sought admittance into the registry yet due to the lag time between publication start date and admittance date in to DOAJ. This brief lag time however, will always remain in effect since after the development of a new OA nursing journal, it must meet the standards set by DOAJ before admittance to the registry. Additionally, this research did not involve subscription-based nursing journals that convert to OA after a 12 to 18 month delay/embargo, or offer the hybrid option, where subscription and OA articles are found within the same journal issue. Identifying these options with major publishers will be a next step in characterizing the science of nursing using mixed OA resources.

\section{Implications for nursing}

Nurse scientists have responsibilities to disseminate their results to the broadest possible audience. For this to happen, we must educate ourselves to the new trends in scholarly publishing and take advantage of this new publishing platform. To globalize our science, we must be willing to pay minimal fees so that others globally can take advantage of our scholarly work; besides, many options exist to fund APCs. Authors can: a) add line item funding requests in grant proposals for the dissemination of results in OA journals, b) apply for publication seed monies from departments, institutions, or institutional libraries, or c) have fees waived by the publisher if an institution is a member of the publisher, or d) have fees waived by the publisher due to author's financial hardship. As this research shows, it has been over 20 years since nursing first began limited involvement in the Open Access movement. The global nursing community can see the science of nursing through the lens of OA journals. Publishers of these journals must strive to showcase the best knowledge and evidence represented in their country since that is what nurse scholars around the world will have access to. If nursing is to provide current evidence-based information, nurse clinicians around the globe must have access to the same information. With the promise of OA, simultaneous access around the globe will further the science of nursing

There must be changes in nursing curricula at all levels and hospital orientation programs. It is not sufficient to help students learn how to use institutional subscription-based libraries, because once students finish a program of study, these same nurses will not have access to academic libraries and the skill of using fee-based databases may be obsolete. Therefore, adding didactic and practice materials about OA access in the curricula will help students acquire the knowledge, skills, and attitudes to use Open Access journals from all over the world. Knowing how to search key OA sites will be critical for life-long learning skills.

Dissemination science is an emerging field - this article offers an approach to getting information cheaply and efficiently using the OA publishing platform. If nurses can access full-text current 
information for free, they will be able to do evidence-based practice which will improve patient outcomes, as well as experience increased fulfillment in their career as a professional nurse (Melnyk et. al. 2010). Increasing participation in the OA movement promises to be a major contributor in globalizing nursing science.

Conflict of Interests: The author declares no conflict of interest.

\section{References}

[1] Amaral P \& Carvalho AM (2014) Portuguese-Spanish Interfaces: Diachrony, synchrony, and contact. John Benjamins Publishing Co, Philadelphia, pp 175-202.

[2] American Association of Colleges of Nursing (2008) the essentials of baccalaureate education for professional nursing practice. Essential IV Available at: www.aacn.nche.edu/dnp/pdf/essentials.pdf. Accessed January 23, 2015.

[3] Atchison A \& Bull J (2015) Will Open Access Get Me Cited? An Analysis of the Efficacy of Open Access Publishing in Political Science. Political Science \& Politics, 48(1), 129-137. http://dx.doi.org/10.1017/S1049096514001668.

[4] Björk B \& Solomon D (2012) Open access versus subscription journals: a comparison of scientific impact. BMC Medicine, 10, 73 http://dx.doi.org/10.1186/1741-7015-10-73.

[5] Budapest Open Access Initiative (2002, February 14) Available at http://www.budapestopenaccessinitiative.org/read. Accessed March 3, 2015.

[6] Edwards R \& Shulenburger D (2003) The High Cost of Scholarly Journals (and what to do about it). Change, 35(6), 10-19. http://dx.doi.org/10.1080/00091380309604123.

[7] HIMSS (2011, June 17) Position Statement on Transforming Nursing Practice through Technology \& Informatics. Available at: http://www.himss.org/library/nursing-informatics/position-statement. Accessed March 2, 2015

[8] ICN (2014) Position Statement: The right to connect via information and communication technology. Available at http://www.icn.ch/publications/position-statements/. Accessed March 3, 2015.

[9] INANE Predatory Publishing Practices Collaborative (2014) Predatory Publishing: What every editor needs to know. Nurse Author \& Editor, 24(3), 1.

[10]Kaiser J (2010) free journals grow amid ongoing debate. Science, 329(5994), 896-898. http://dx.doi.org/10.1126/science.329.5994.896.

[11]Kurata K, Morioka T, Yokoi K, \& Matsubayashi M (2013) Remarkable Growth of Open Access in the Biomedical Field: Analysis of PubMed Articles from 2006 to 2010. PLoS One, 8(5), e60925. http://dx.doi.org/10.1371/journal.pone.0060925.

[12] Liesengang TJ (2013) The Continued Movement for Open Access to Peer-Reviewed Literature. American Journal of Opthamology, 156, 423-432. http://dx.doi.org/10.1016/j.ajo.2013.04.033.

[13]Melnyk BM, Fineout-Overholt E, Giggleman M, \& Cruz R (2010) Correlates among cognitive beliefs, EBP implementation, organizational culture, cohesion and job satisfaction in evidence-based practice mentors from a community hospital system. Nursing Outlook, 58(6), 301-308. http://dx.doi.org/10.1016/j.outlook.2010.06.002.

[14]National League for Nursing Position Statement (2008) preparing the next generation of nurses to practice in a technology-rich environment: An informatics agenda. Available at: www.nln.org/aboutnln/positionstatements/informatics 052808.pdf. Accessed February 15, 2015.

[15]National Research Council Canada (2009) PubMed Central Canada: Making Canadian health research accessible to all. Available at: http://cisti-icist.nrc-cnrc.gc.ca/eng/services/cisti/pubmed-centralcanada/index.html. Accessed March 5, 2015.

[16] Nature Publishing Group (2014) Available at: http://www.nature.com/ncomms/about/index.html . Accessed January 30, 2015.

[17]Nick JM (2011) Open Access Part I: The Movement, the Issues, and the Benefits. The Online Journal of Issues in Nursing, 17(1), doi: 10.3912/OJIN.Vol17No01PPT02.

[18]Nick JM (2013, August 6) Reply by author to Guild on "Open Access Part I: The Movement, The Issues, and the Benefits" and "Open Access Part II: The Structure, Resources, and Implications for Nurses". Online Journal of Issues in Nursing, 18(3).

[19]NIH Public Access Policy (2008) Division G, Title II, Section 218 of PL 110-161 (Consolidated Appropriations Act, 2008). Available at: Available at: http://publicaccess.nih.gov/policy.htm. Accessed March $15,2015$.
[20]Research Information Network (2013) Finch Report: Report of the Working Group on Expanding Access to Published Research Findings - the Finch Group. Available at: http://www.researchinfonet.org/publish/finch/. Accessed March 7, 2015.

[21] Sheets W (2014, May 14) Understanding Orthography and its Implications for English Language Learners. Available at: http://lcosu.blogspot.com/2012/04/understanding-orthographyand.html. Accessed March 7, 2015.

[22] Solomon DJ \& Björk B (2012) a study of open access journals using article processing charges. Journal of the American Society for Information Science and Technology, 63(8), 1485-1495. http://dx.doi.org/10.1002/asi.22673.

[23] Wellcome Trust (2013, October) Open Access Policy: Position statement in support of open and unrestricted access to published research. Available at: http://www.wellcome.ac.uk/About-us/Policy/Policy-andposition-statements/WTD002766.htm. Accessed February 28, 2015.

[24] Wolrabe K \& Birkmeier D (2014, June 28) does open access articles in Economics offer a citation advantage? MPRA Paper No. 56842. Available at: http://mpra.ub.uni-muenchen.de/56842/. Accessed March 17, 2015.

[25] World Health Organization (2014) WHO's vision for information sharing. Available at: www.who.int/about/who reform/change at who/issue4/informationsharing/en/index.html. Accessed February 27, 2015. 